\title{
EI Necesario Reconocimiento del Principio de Justicia Contractual
}

\author{
The necessary acknowledgement for the principle of contractual justice
}

JOAQUÍN EMILIO ACOSTA RODRÍGUEZ

Coordinador de investigaciones y profesor de la Maestría en Derecho Contractual Público y Privado de la Universidad Santo Tomás de Bogotá. Con posgrado (DSU) en Derecho Comercial de la Universidad de París II (Panthéon-Assas). Máster en Derecho Privado General de la Universidad de París II (Panthéon-Assas). Profesor en pregrado de las asignaturas de obligaciones y contratos en las Universidades

Santo Tomás y Sergio Arboleda. Correo electrónico: joaqocsta@hotmail.com .

Coordinator of investigations and professor of the Masters degree in public and private contractual law from the Universidad Santo Tomás of Bogotá. Postgraduate degree (DSU) in commercial law from the University of Paris II (Panthéon-Assas).

Master in general private law of the University of Paris II (Panthéon Assas).

Professor of undergraduate degrre in the obligations and contracts classes in the Universidad Santo Tomás and Universidad Sergio Arboleda.. Correo electrónico:

joaqocsta@hotmail.com

Fecha de recepción: 22 de junio de 2011 Fecha de evaluación: 14 de septiembre de 2011 Fecha de aprobación: 16 de septiembre de 2011

RESUMEN: Las nuevas realidades políticas y económicas ameritan repensar las categorías básicas del derecho de contratos, especialmente sus principios generales. A tal punto, que es imprescindible reconocer que los principios y tendencias que dominan la teoría posmoderna del contrato en algunos ámbitos se complementan, pero de manera indudable en otros aspectos se contradicen ampliamente. Para solventar la presente problemática, debe tenerse presente que 
la noción de Principios Generales del Derecho así como la naturaleza relativa del imperativo de seguridad jurídica se enmarcan dentro de la más pura tradición romanista. En realidad, esta contradicción genera una tensión entre los imperativos de libertad y justicia contractual.

PALABRAS CLAVES: Principios generales del Derecho, seguridad jurídica , teoría posmoderna de los contratos.

ABSTRACT: The new political and economic realities need a rethinking on the basic categories of contractual law, specially its general principles. Up to a point, where it is essential to recognize that the principles and tendencies that dominate the postmodern theory of contract in certain contexts complement each other, but undoubtedly in other aspects they contradict themselves widely. To solve this problematic, it must be taken into account that the notion of general principles of law, as well as the relative nature of the imperative need for juridical security, are framed inside the most pure roman tradition. Really, this contradiction generates tension between the imperatives of freedom and contractual justice.

KEY WORDS: General principles of law, juridical security, postmodern theory of contracts. 
Tipo de Artículo: Reflexión Académica

\section{INTRODUCCIÓN}

La misión esencial del Derecho es la de resolver de manera pacífica los distintos conflictos generados a raíz de la convivencia social. Para ello es necesario que haya concordancia entre la realidad y lo jurídico. Vale la pena preguntarse si tal presupuesto se verifica a nivel regional, incluyendo especialmente el tema económico y contractual. Como se ha explicado en trabajos anteriores el Derecho de Contratos de tradición continental remonta sus orígenes al régimen de la antigua Roma. Y tal entorno es esencialmente diferente al actual. En efecto, la economía de la sociedad romana era de tipo mayoritariamente agrario y junto con el aporte medieval, de corte eminentemente feudal.

Lo anterior indica una creciente brecha entre el régimen económico-contractual y la realidad material actual. Fenómenos históricos como la Revolución Industrial, la cuestión social, la sociedad de consumo y especialmente la globalización han transformado a tal punto las dinámicas transaccionales que exigen un repensamiento del Derecho de Contratos. No es necesario alegar una inexistente inmutabilidad económico-social desde la Revolución Industrial. Basta con constatar que las realidades actuales son radicalmente disímiles a las de la época de promulgación de los Códigos decimonónicos de nuestra región. Por ejemplo, gracias a la industrialización nace la clase social o el gremio de los industriales, 
quienes transformaron la cadena de distribución de bienes y servicios. Así, se encuentran eslabones económicos inexistentes en un circuito artesanal, como es el caso de la producción y distribución en masa, con las correspondientes consecuencias generadas a partir de esta nueva realidad.

No obstante lo anterior, hay razones para cuestionar que el contexto económico contemporáneo sea absolutamente distinto al del mundo anterior al siglo XIX. En consecuencia, las nuevas realidades coexistirían con constantes históricas. A manera de ejemplo sobre permanencias económicas, se puede citar la compraventa como el principal y más importante contrato, desde el mundo antiguo hasta nuestros días. La tarea entonces será la de identificar esta dialéctica entre lo nuevo y lo persistente en el mundo contractual contemporáneo o posmoderno.

Para ello se tomará como punto de partida la creación de entidades como el FMI o la OMC, la cuales han generado un grado de injerencia externa a las prácticas económicas nacionales sin precedente alguno. El ideal de evitar futuros desastres económicos a escala mundial así como el objetivo de "... facilitar la expansión y el crecimiento equilibrado del comercio internacionap"1 desembocó en la afectación no sólo del sistema global de aranceles, sino en el desarrollo de una serie de prácticas comerciales y mecanismos de solución de conflictos que generaron una ruptura drástica respecto a los tradicionales enfoques mercantilistas para dar paso

\footnotetext{
${ }^{1}$ Artículo $1^{\circ}$ del Acuerdo de Bretton Woods.
} 
una nueva era de libre comercio ${ }^{2}$. En nombre de altos ideales se establecieron un conjunto de planes e instituciones tendientes a aumentar el comercio internacional, el cual generaría un marco de cooperación nuevo del cual todos saldríamos beneficiados.

Más de sesenta años después, se evidencia el alto nivel de ingenuidad desplegado por los líderes mundiales que se aferraron a las anteriores ideas. Pero igualmente se debe cuestionar el pensamiento jurídico tradicional, en cuanto a su capacidad para enfrentar eficazmente las nuevas realidades.

Adicionalmente la globalización económica se ha acelerado gracias a las nuevas tecnologías que facilitan la movilidad de la información, los capitales y las personas, determinando un nivel creciente de la inversión por parte de multinacionales a lo largo del planeta, América Latina incluida. Realidades regionales como el Pacto Andino -hoy CAN- o Mercosur se inscriben en el proceso global de conformación de bloques económicos tendientes a generar integración comercial. Ello, desde luego, confluye correlativamente en un debilitamiento del poder estatal, y específicamente en la posibilidad de influir en la

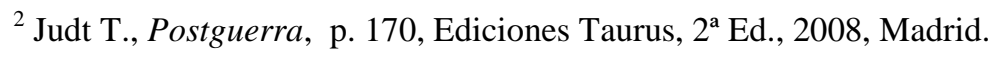


política económica, gracias a una serie de reformas ${ }^{3}$ implementadas en la región a partir de la década de los ochentas en el siglo anterior ${ }^{4}$.

En efecto, cuando nuestra región acogió con los brazos abiertos el régimen del Código Civil francés a lo largo del siglo XIX, lo hizo seducida por las premisas revolucionarias de la libertad e igualdad. En materia jurídica la principal herramienta fue el postulado de la autonomía de la voluntad privada, considerada el punto de equilibrio entre la necesidad de proteger los intereses de los contratistas así como la salvaguarda del interés general. Sin embargo en el mundo de hoy las fórmulas de libertad e igualdad ya no se exhiben tan irrefutables. Los contratos de la actualidad en su gran mayoría ya no son el resultado de fuerzas e intereses equilibrados y libre discusión entre iguales. Ello podía creerse en un mundo regido por realidades agrícolas y artesanales. Pero la globalización trajo consigo los procesos de integración económica y privatización, promoviendo que los mercados estén bajo el dominio de los grandes conglomerados, generando innegables riesgos para los consumidores $^{5}$ y los pequeños competidores comerciales.

\footnotetext{
${ }^{3}$ Las reformas económicas recayeron en aspectos como apertura comercial, delimitación del intervencionismo del Estado en materia económica, y flexibilización laboral y cambiaria. Tales procesos fueron supervisados por el FMI y el Banco Mundial.

${ }^{4}$ Sánchez C., El Impacto de la Globalización: Aspectos Económicos y Políticos en América Latina, in Globalización, Integración Económica y Derechos Humanos, p. 195 y ss., Universidad Sergio Arboleda, 2005, Bogotá.

${ }^{5}$ Ortega M., Mecanismos de Defensa Frente a las Cláusulas Abusivas en los Contratos Internacionales, in Globalización y Derecho Mercantil, p. 14, Biblioteca Jurídica Diké, 2008, Medellín.
} 
Fundado en el pensamiento liberal del siglo XIX se entendió que era el legislador el encargado de fijar los límites de la autonomía negocial y de esta manera preservar la justicia y la equidad. Correlativamente, el juez era un simple instrumento de la ley, considerada casi como un instrumento sagrado al ser la "expresión de la voluntad popular". El esquema era algo admisible bajo un sistema en que el contratante no detentaba el poder de imponer a su contraparte el clausulado. Pero en un mundo post-industrial y globalizado se denuncia reiteradamente la necesidad de que el Estado ejerza un papel interventor en aras de prevenir, corregir y sancionar los frecuentes abusos cometidos por la parte contractual que detenta una posición dominante.

Lo anterior nos lleva al sempiterno problema de encontrar el punto de equilibrio entre libertad (económica) y justicia (contractual). De ahí que se entienda actualmente que el Derecho tiene que generar -especialmente mediante la protección efectiva de los derechos humanos- aquella medida de libertad que al tiempo reconozca la necesidad de acatar un mínimo de deberes (v.gr. el respeto por el derecho ajeno, especialmente de aquel que es más vulnerable).

Esto nos lleva a indagar sobre el problema de la validez de una norma jurídica (contractual, para el caso que nos interesa) que no es coherente con la realidad actual. Respuestas elaboradas a partir de una "teoría del poder" o "del reconocimiento" son las tradicionales. Sin embargo, ¿tales visiones serán acordes con las realidades generadas por la globalización económica y el objetivo de 
salvaguarda de los derechos fundamentales? Cimentar la validez de un régimen en el dogma de la representación de la comunidad mediante el legislador parlamentario es desconocer la pérdida de soberanía del Estado Nación en la era global. De ahí que actualmente se afirme que la validez del Derecho (su legitimidad material) no pueda residir en la voluntad del legislador o en el consenso de la sociedad ${ }^{6}$, pues de lo contrario una norma parlamentaria atentatoria de un derecho fundamental tendría que ser aceptada como derecho vinculante. Retomando planteamientos kantianos y aristotélicos se recuerda que la persona (y por ende el comerciante así como el industrial) por esencia convive en sociedad, por lo que debe compartir responsabilidades y no sólo derechos. De ahí que se hayan dejado de lado las teorías que propugnaban por una separación tajante entre moral y derecho, y se reconozca en la era global que lo jurídico está relacionado con los valores, entre los cuales el más elemental es el de la justicia. Por lo tanto la seguridad jurídica (incluida la de las transacciones económicas) se refiere a determinadas normas de Derecho, no a todas. ¿A cuáles entonces? A aquellas normas que se abstengan de violar evidentemente un imperativo mínimo de justicia (como es el caso de respetar los derechos fundamentales); en contrapartida, el juez de contratos no deberá solucionar el caso aplicando una norma que, si bien ha sido proferida por la autoridad competente, por diversas razones (v.gr. históricas, políticas) es evidentemente ilegítima. Este es el origen del debate entre validez formal versus validez material del Derecho. Por supuesto, la idea de justicia depende de determinadas circunstancias en un momento

\footnotetext{
${ }^{6}$ Kaufmann A., Filosofía del Derecho, p.391. Universidad Externado, 2006, Bogotá.
} 
histórico dado ${ }^{7}$. Pero es innegable que en la era global tiende a expandirse el culto por los derechos humanos. De ahí que se plantee que no toda norma jurídica sea válida. Ello incita a un profundo análisis acerca de las normas que regulan las transacciones contractuales consignadas en los viejos Códigos estatales e incluso los preceptos contenidos en la Nueva Lex Mercatoria. Desde luego, esto implica la superación del dogma de aplicación de una norma formalmente válida pero materialmente atentatoria de Derechos fundamentales.

Se impone entonces la necesidad de desarrollar criterios objetivos que permitan identificar lo materialmente válido en la era global, así como las herramientas para combatir los abusos de posición dominante, así sus técnicas (contractuales, especialmente) sean formalmente válidas. Para ello es menester retomar la constatada idea de que las revoluciones industriales, el auge del capitalismo, materializado en la producción y consumo masivos acentuados ahora con la globalización han modificado sensiblemente la estructura socioeconómica ${ }^{8}$ de nuestro entorno. Las nuevas necesidades han determinado nuevos regímenes jurídicos en el mundo de los contratos: fiducia mercantil, suministro así como contratos de garantía y seguros; el contrato de arrendamiento ha perdido su unidad para adaptarse tanto a las necesidades de habitación como de comercio. A lo anterior se añade el derecho internacional, el cual ha vuelto compleja la

\footnotetext{
${ }^{7}$ V.gr. el ideal de ascetismo del cristianismo primitivo, el espíritu caballeresco de la Edad Media, el racionalismo de la ilustración, el humanismo del clasicismo y hasta el comunismo como ideal del marxismo.

${ }^{8}$ Mantilla F. y Ternera F. (Directores Académicos), Los Contratos en el Derecho Privado, p.xxi. Editorial Legis, 2009, Bogotá.
} 
concepción del contrato de transporte, transferencia de tecnología, distribución, asociación (siendo el joint venture el más representativo), así como los actualmente denominados contratos preparatorios y de aquellos destinados a solucionar conflictos de manera alternativa (como es el caso del contrato de arbitraje). Estas nuevas realidades han generado la emisión de nuevos instrumentos (designados comúnmente como Nueva Lex Mercatoria) que alteran el panorama jurídico de la era global, como acontece con la convención internacional de compraventa de mercaderías ${ }^{9}$ (Esta convención de Viena de 1980 fue aprobada por el Congreso colombiano mediante la ley 518 de 1999).

Las anteriores realidades incitan a repensar el derecho de contratos desde la óptica de los principios generales del derecho.

Noción de Principios Generales del Derecho. Etimológicamente el término latino principium está compuesto por la raíz derivada de pris, que significa «lo antiguo» y «lo valioso» y de la raíz $c p$ que aparece en el verbo capere - tomar- y en el sustantivo caput —cabeza-; Tiene, entonces, un sentido histórico («lo antiguo»), un sentido axiológico («lo valioso») y un sentido jerárquico $\left(\right.$ (cabeza») ${ }^{10}$. Según el Diccionario de la Real Academia Española de la Lengua ${ }^{11}$ el término «principio» significa, entre otros, «punto que se considera como primero en una extensión o cosa», «base, origen, razón fundamental sobre la cual se

\footnotetext{
${ }^{9}$ Op. Cit., p xxxiii y ss.

${ }^{10}$ JIMÉNEZ CANO, Roberto-Marino, Sobre Los Principios Generales Del Derecho. Especial Consideración en Derecho Español, http://www.filosofiayderecho.com/rtfd/numero3/1-3.pdf

${ }^{11}$ www.rae.es
} 
procede discurriendo en cualquier materia», «causa, origen de algo», «cualquiera de las primeras proposiciones o verdades fundamentales por donde se empiezan a estudiar las ciencias o las artes».

Si bien la importancia que ha venido adquiriendo la noción de Principios Generales del Derecho se la debemos a Ronald Dworkin, gracias a su distinción entre "Principio" y "Regla" ${ }^{12}$, lo cierto es que esta concepción se enmarca dentro de la más pura tradición romanista, como bien lo indica nuestra Corte Constitucional, quien a propósito recuerda ${ }^{13}$ :

"Que a los principios así extraídos se les denomine reglas no constituye una audacia del legislador colombiano de 1887. Tal nombre pertenece a la más pura tradición del derecho occidental en su raiz (Sic) romana. Así lo ilustra, con rigurosa documentación, el profesor Hernán Valencia Restrepo en su valioso trabajo sobre los principios generales del derecho. A propósito de la asimilación hecha por el jurista preclásico Antiscio Labeón (año 45 a.c.) del término regla al de norma, escribe: 'Se debe aclarar que la ...sinonimia (regla = norma jurídica) no constituyó novedad alguna, en cuanto a la significación estrictamente jurídica, porque la regla desde siempre se había considerado extraída del derecho vigente, del derecho positivo y, por lo consiguiente, parte integrante de éste, es decir, norma jurídica.' (subraya la Corte). Y para ilustrar mejor su aseveración cita la definición de regla dada

\footnotetext{
${ }^{12}$ ALEXY, Robert, Tres escritos sobre los derechos fundamentales y la teoría de los principios (traducción de Carlos Bernal Pulido), p. 47, Bogotá 2003

${ }^{13}$ Sentencia C-083/95
} 
por Paulo: "La regla es una proposición que expone brevemente el derecho vigente. No se toma el derecho vigente de la regla sino la regla del derecho vigente. Así, pues, mediante la regla se transmite una breve descripción de las normas vigentes y, como dice Sabino, es como un resumen del derecho, que si falla en algo resulta inútil". (Subrayas fuera del texto).

Y más adelante agrega:

'La antecedente interpretación se confirma con la de los glosadores (siglos XII y XIII), para quienes la definición de regla del Digesto ('la regla es como un resumen del derecho vigente'), patentiza que es una generalización inducida de los casos singulares: la regla reduce varios casos a uno. '...si las reglas son generalizaciones inducidas de los casos resueltos por las normas particulares del derecho vigente, fuerza es concluir que tienen la misma naturaleza jurídica de las normas de las cuales son extraídas. Más escuetamente, las reglas son normas jurídicas como lo son las normas particulares que han resuelto los casos. (Subrayas de la Corte). Claro está que en nuestro derecho, como en el de los países europeos donde se cumplió el fenómeno de la recepción, al sustituirse las normas generales al casuismo, es a partir de ellas que se lleva a término la inducción que concluye en la formulación de la regla."

Así pues, entendiendo que un Principio General del Derecho "es como un resumen del derecho vigente", mediante "generalizaciones inducidas de las 
normas particulares", tenemos que esta concepción jurídica ha sido reconocida en nuestro ordenamiento nacional por la ley 153 de $1887^{14}$. En este sentido, nuestra Corte Suprema de Justicia en Sentencia de 23 de junio de 1.958 sobre el punto estableció: "(...) El ordenamiento jurídico no está constituido por una suma mecánica de textos legales. No es, como muchos pudieran creerlo, una masa amorfa de leyes. Todo orden jurídico está integrado por ciertos principios generales, muchos de ellos no enunciados concretamente por el Código Civil, pero de los cuales, sin duda, se han hecho aplicaciones concretas"15 (NFT).

Por supuesto, la concepción de los Principios ha evolucionado desde la época romana, y hoy en día se les emplea para impedir que se sigan cometiendo los yerros e injusticias cometidos a raíz de los planteamientos difundidos por la escuela moderna de la interpretación exegética. Es por ello que el artículo 230 de nuestra Constitución reconoce la existencia de los Principios y le otorga un papel dinámico en el proceso de la decisión judicial, como bien lo señala nuestra Corte Constitucional, quien a propósito indica ${ }^{16}$ :

"Para la Corte Constitucional es claro que el inciso primero del artículo 230 no tuvo la finalidad de excluír (Sic) la costumbre del ordenamiento jurídico. Lo que se buscó fue afirmar la autonomía de los jueces, poner de presente que su misión se limita a aplicar el derecho objetivo, haciendo a un lado

\footnotetext{
${ }^{14}$ Artículos $4^{\mathrm{o}}$ y $8^{\circ}$.

${ }^{15}$ G. J., T LXXXVIII, Pág. 232.

${ }^{16}$ Sentencia C-224/94
} 
toda consideración diferente y todo poder extraño. No sobra advertir que habrá casos en que el juez deba aplicar los principios generales del derecho, que el inciso segundo llama criterios auxiliares, haciendo a un lado el texto de la ley, para no incurrir en el pecado que señala el aforismo latino: derecho estricto, injusticia suprema. Se dice esto para indicar que no puede considerarse al juez como un autómata, esclavo de la norma estricta. Por ley debe entenderse el ordenamiento jurídico como un todo." (NFT)

Ahora bien, el anterior planteamiento demuestra que la posmodernidad jurídica ha marcado su propia impronta en la concepción de los Principios; así por ejemplo, si bien desde la antigüedad se entendió que al ser un resumen del Derecho vigente, al intérprete le correspondía "descubrirlos" por vía de inducción (Supra), actualmente se entiende y reconoce que los Principios sirven igualmente para que el juez desempeñe una función creadora mediante el desarrollo jurisprudencial. Y no solamente esto: lícito es que el juez pueda crear Principios, en aras de adecuar el ordenamiento positivo a las nuevas necesidades sociales. Aún más, tal papel creador no solamente se encamina a adaptarse a los cambios, sino igualmente a transformar la realidad social, acercándola al objetivo señalado en el preámbulo de nuestra Constitución: la creación de un orden político, económico y jurídico justo. Así pues, la jurisprudencia goza de un papel creador, incluso en materia de Principios Generales del Derecho. Dicho en otras palabras, gracias a los Principios el juez es en la posmodernidad un agente racionalizador e integrador del Derecho. 
Nuevamente citamos a nuestra Corte Constitucional, quien al respecto y basándose en normatividad del siglo XIX ha manifestado ${ }^{17}$ :

"Esta función creadora del juez en su jurisprudencia se realiza mediante la construcción y ponderación de principios de derecho, que dan sentido a las instituciones jurídicas a partir de su labor de interpretación e integración del ordenamiento positivo. Ello supone un grado de abstracción o de concreción respecto de normas particulares, para darle integridad al conjunto del ordenamiento jurídico y atribuirle al texto de la ley un significado concreto, coherente y útil, permitiendo encausar este ordenamiento hacia la realización de los fines constitucionales. Por tal motivo, la labor del juez no pueda reducirse a una simple atribución mecánica de los postulados generales, impersonales y abstractos consagrados en la ley a casos concretos, pues se estarían desconociendo la complejidad y la singularidad de la realidad social, la cual no puede ser abarcada por completo dentro del ordenamiento positivo. De ahí se derivan la importancia del papel del juez como un agente racionalizador e integrador del derecho dentro de un Estado y el sentido de la expresión "probable" que la norma acuña a la doctrina jurisprudencial a partir de la expedición de la Ley 169 de 1896. La palabra probable, que hace alusión a un determinado nivel de certeza empírica respecto de la doctrina, no implica una anulación del sentido normativo de la jurisprudencia de la Corte Suprema.

\footnotetext{
${ }^{17}$ Sentencia C-836/01
} 
( ...)

Corresponde a los jueces, y particularmente a la Corte Suprema, como autoridad encargada de unificar la jurisprudencia nacional, interpretar el ordenamiento jurídico. En esa medida, la labor creadora de este máximo tribunal consiste en formular explícitamente principios generales $y$ reglas que sirvan como parámetros de integración, ponderación e interpretación de las normas del ordenamiento. Sin embargo, esta labor no es cognitiva sino constructiva, estos principios y reglas no son inmanentes al ordenamiento, ni son descubiertos por el juez, sino que, como fuentes materiales, son un producto social creado judicialmente, necesario para permitir que el sistema jurídico sirva su propósito como elemento regulador y transformador de la realidad social. Con todo, para cumplir su propósito como elemento de regulación y transformación social, la creación judicial de derecho debe contar también con la suficiente flexibilidad para adecuarse a realidades y necesidades sociales cambiantes. Por lo tanto, no se puede dar a la doctrina judicial un carácter tan obligatorio que con ello se sacrifiquen otros valores y principios constitucionalmente protegidos, o que petrifique el derecho hasta el punto de impedirle responder a las necesidades sociales." (NFT)

Con base en la anterior exposición podemos establecer que el contrato posmoderno es regido por tres principios esenciales: principio de la libertad contractual, principio de la justicia contractual y el principio de la confianza en la 
voluntad declarada. Sin embargo, la influencia respectiva de cada uno de estos principios así como su combinación mutua observan variaciones fundamentales en razón de los diferentes derechos nacionales; éstos a su vez son el producto de las diferentes evoluciones económicas, sociales y políticas ${ }^{18}$.

\section{1.- Principio de la Libertad Contractual}

Nuestro Código Civil -como la totalidad de códigos occidentales del siglo XIX- es producto de una época individualista, liberal y capitalista. Para algunos autores incluso un código posmoderno como el BGB sigue adhiriéndose en lo esencial al dogma de la autonomía de la voluntad, en donde el principio de la libertad contractual es la manifestación más notoria ${ }^{19}$. Nuestra Corte Constitucional se ha dedicado a sintetizar la naturaleza de la autonomía de la voluntad privada en los siguientes términos ${ }^{20}$ :

"La autonomía de la voluntad privada consiste en el reconocimiento mas o menos amplio de la eficacia jurídica de ciertos actos o manifestaciones de voluntad de los particulares. En otras palabras: consiste en la delegación que el legislador hace en los particulares de la atribución o poder que tiene de regular las relaciones sociales, delegación que estos ejercen mediante el otorgamiento de actos o negocios jurídicos.

La mayor o menor amplitud en la consagración positiva del postulado de la autonomía de la voluntad privada o, lo que es lo mismo, en el

\footnotetext{
${ }^{18}$ PEDAMON, (M.), Le contrat en Droit allemand, 2004, Paris, LGDJ, n 21.

${ }^{19}$ PEDAMON, (M.), Le contrat en Droit allemand, 2004, Paris, LGDJ, n 22.

${ }^{20}$ Sentencia No. T-338/93
} 
señalamiento del campo del campo de acción del acto o negocio jurídico que es su expresión normal, depende principlamente (Sic) del grado de cultura y desarrollo de cada pueblo y de las concepciones filosóficopolíticas en que se inspire cada legislador." (NySFT)

Precisamente por lo señalado por nuestro alto tribunal constitucional, no deja de llamar la atención que ni los redactores del Código Civil francés ni sus homólogos del Código Civil colombiano se adhirieron enteramente a la teoría de la autonomía de la voluntad privada $^{21}$ (Infra). De cualquier manera, tanto en Francia y Latinoamérica como Alemania, este principio recubre a su vez distintos tipos de libertades ${ }^{22}$ :

-libertad de contratar o no contratar (Abschlussfreiheit, en Derecho Alemán) -libertad de escoger a su contraparte (Freiheit der Partnerwahl) -libertad de diseñar el contenido del contrato (Gestaltungsfreiheit); esta libertad autoriza a las partes a implementar como les parezca sus vínculos contractuales, a alejarse total o parcialmente de los modelos de contratos reglamentados de manera no imperativa por las normas de orden público (Infra). Igualmente permite la creación de tipos contractuales nuevos, ya sea adaptando elementos de las reglas tradicionales o forjándolos de manera completamente original.

-libertad de la forma (Formfreiheit) o consensualismo; a pesar de que nuestra legislación nacional no menciona esta libertad de manera expresa, nuestros

\footnotetext{
${ }^{21}$ LARROUMET, (C.), Droit Civil, t. III Les obligations, Le contrat, 2003, Paris, Economica, $\mathrm{n}^{\circ} 116$.

${ }^{22}$ PEDAMON, (M.), Le contrat en Droit allemand, 2004, Paris, LGDJ, nº 22.
} 
contratos -en principio- no se encuentran sometidos a ninguna forma específica, pudiendo ser concluidos verbalmente.

Se puede entender que el principio de la libertad contractual está contenido implícitamente en el artículo 16 de nuestra Constitución Nacional que garantiza a toda persona el "derecho al libre desarrollo de la personalidad", tal y como acontece en Alemania, en donde se entiende que el artículo $2^{\circ}$ de su ley fundamental tácitamente habla de la libertad contractual al reconocer el libre desarrollo de la personalidad ${ }^{23}$.Adicionalmente, esta libertad concuerda perfectamente con nuestra libertad de empresa, reconocida expresamente en el artículo 333. En efecto, nuestra Corte Constitucional lo ha precisado en los siguientes términos ${ }^{24}$ :

"La segunda garantía constitucional en la cual se fundamentan las facultades del testador es la autonomía privada de la voluntad y aunque no existe una norma en la Constitución que la contemple en forma específica, ella se deduce de la libertad y el libre desarrollo de la personalidad, respectivamente, los que sirven de sustento para afirmar que se ha de reconocer a las personas la posibilidad de que obren según su voluntad, siempre y cuando no atenten contra el orden jurídico y los derechos de los demás. Adicionalmente, se encuentra una serie de normas constitucionales garantes de ciertos derechos, cuyo ejercicio supone la autonomía de la voluntad." (NFT)

\footnotetext{
${ }^{23}$ PEDAMON, (M.), Le contrat en Droit allemand, 2004, Paris, LGDJ, nº 22.

${ }^{24}$ Sentencia C-660/96
} 
En la época de elaboración de los Códigos Civiles alemán, francés o latinoamericanos reinaba una gran confianza en las virtudes y eficacia del liberalismo. Se esperaba que el libre juego de la autonomía contractual permitiría la realización de la armonía social en el proceso de distribución de bienes y riquezas. Los redactores de los diferentes códigos modernos razonaron a partir del prototipo de un particular autónomo, amo de sus decisiones que disponía independientemente de sus bienes y recursos materiales. Este individuo modélico se consideraba provisto de una voluntad libre, informada, e igual a la del resto de miembros del conglomerado social. En consecuencia, tal contratante debía ejecutar fiel y estrictamente los compromisos adquiridos ${ }^{25}$. Esta visión dogmática se verifica en el principio pacta sunt servanda. Nuevamente cedemos la palabra a nuestra Corte Constitucional, quien explica el basamento filosófico que subyace en esta visión ${ }^{26}$ :

“Para algunos de los filósofos del siglo XVIII como Kant, Hobbes y Rousseau, autores de teorías políticas que fundan gran parte del derecho occidental contemporáneo, la voluntad es la principal fuente de las obligaciones ya sea que se manifieste directamente, a través de acuerdos suscritos por los particulares, o indirectamente, a través de la ley en forma de voluntad general. El razonamiento presupone que los hombres son iguales, de tal forma que si dos personas consienten en algo sin presión alguna, lo único que los determina es el libre ejercicio de

\footnotetext{
${ }^{25}$ PEDAMON, (M.), Le contrat en Droit allemand, 2004, Paris, LGDJ, n 22.

${ }^{26}$ Sentencia C-660/96
} 
su voluntad; la única causa de prometer algo es que así se quiere. A su vez, estos argumentos sirven para trazar los lineamientos básicos de la actividad estatal; por un lado queda claro que es necesario garantizar las condiciones ideales para posibilitar los acuerdos entre particulares, esto es, impedir que alguien sea sometido mediante la fuerza a contratar, a consentir; pero, por otro lado, también se deduce que dentro de las funciones estatales no está la de intervenir en la órbita de los particulares, pues si garantizando la libertad de las partes se mantiene la equidad, mal haría el Estado en alterarla al entrometerse."

Hoy se entiende que el anterior modelo ya no es conforme con la sociedad posmoderna, caracterizada por sistemas de producción y distribución en masa dominados por multinacionales que emplean de manera intensa la publicidad y demás técnicas contemporáneas de marketing, el desarrollo del crédito, o la apertura de fronteras (Supra). A todo ello se debe añadir la complejidad creciente de los productos y servicios, los cuales afectan directamente los diferentes modelos contractuales ${ }^{27}$.

En esta nueva realidad muchos contratantes, consumidores así como pequeños empresarios especialmente, se encuentran desprotegidos frente a agentes económicos mucho más poderosos. Esta es la razón por la cual la teoría posmoderna del contrato ha procurado proteger a la parte débil de este tipo de

\footnotetext{
${ }^{27}$ PEDAMON, (M.), Le contrat en Droit allemand, 2004, Paris, LGDJ, $n^{\circ} 23$.
} 
vínculos no sólo mediante disposiciones legales o aún constitucionales, sino igualmente reinterpretando las disposiciones tradicionales, tales como las relativas a los vicios del consentimiento ${ }^{28}$. Así las cosas aparece un derecho de retractación o arrepentimiento con posterioridad a un período de reflexión, a pesar del anteriormente mencionado principio pacta sunt servanda. Tal evolución implica un pasaje progresivo de una concepción jurídica y formal de la libertad contractual a un acercamiento efectivo y material de este derecho, como un eco de las preocupaciones por la materialización de un orden jurídico justo ${ }^{29}$. Es por ello que la Corte Constitucional ha señalado ${ }^{30}$ :

“Esta tesis (los hombres son iguales) fue posteriormente replanteada por teorías socialistas que objetan la supuesta igualdad entre los ciudadanos, para así llegar a concluir que el hecho de que ambas partes suscriban el pacto libremente, no es garantía de justicia. Afirman que no hay razón para pensar que la intromisión del Estado sea lesiva, pues no existe en realidad equidad alguna qué proteger; es más, la voluntad no es capaz de obligar por sí sola, es necesaria la intervención de la sociedad. En consecuencia, se ha aceptado el establecimiento de límites a la autonomía de la voluntad. Esta tendencia orientada a reducir el voluntarismo que inspiraba al derecho, pese a que logró varios de sus objetivos, no llegó nunca a suprimir el papel preponderante que ocupa la voluntad en el ámbito jurídico, en especial en el área del derecho privado.

\footnotetext{
${ }^{28}$ PEDAMON, (M.), Le contrat en Droit allemand, 2004, Paris, LGDJ, n 23.

${ }^{29}$ PEDAMON, (M.), Le contrat en Droit allemand, 2004, Paris, LGDJ, n 23.

${ }^{30}$ Sentencia C-660/96
} 
En el Código Civil colombiano de 1887 se consagraron tanto la visión voluntarista imperante, como los límites a la autonomía de la voluntad que por entonces se aceptaban: el orden público y la buenas costumbres; prueba de ello son, entre otros, los artículos 16, 1151, 1518, 1524 y 1532. Se puede decir, entonces, que la institución mencionada, aunque limitada, adquirió un lugar preponderante y fundamental dentro del sistema.

Sin embargo, el derecho, en cuanto fenómeno social, no es susceptible de sustraerse a los cambios. Los nuevos rumbos de la $\underline{\text { historia, junto a las teorías contemporáneas, lograron que se redujera }}$ el ámbito concedido al libre ejercicio de la voluntad. En primer lugar, los límites impuestos a dicha autonomía se incrementaron al incluir dentro de la noción de orden público, no sólo la esfera política, sino también la económica y los derechos humanos. En segundo lugar el auge del derecho comercial y las nuevas formas para negociar, le restaron la importancia que antaño tenía. La complejidad de los negocios que se realizan ha incrementado la celebración de contratos "tipo" o de contratos de adhesión, en los cuales el papel que juega el operador jurídico queda limitado a aceptar o rechazar unas cláusulas previamente redactadas por otro. (NySFT) 
Es por ello que el postulado de la libertad se enmarca dentro del criterio según el cual el ejercicio de los derechos y las libertades está sujeto a la ley, ya que, como lo declaró reiteradamente la Corte Suprema de Justicia, "la libertad no es la incondicionalidad de la voluntad; el hombre en sociedad debe arreglar su voluntad a la ley, para hacer compatibles sus derechos con los de los demás. Se es libre dentro de la ley, al ejercer los derechos en ella reconocidos. Sin la protección y garantía de la ley, nadie tiene derecho y se está a merced del más fuerte'B1.

"La libertad, toda libertad, no tiene significado sino en la vida social, que es el objeto del derecho. Es un concepto y un valor intelectual en función comunitaria. Por eso es relativo. El orden jurídico implica necesariamente una modelación de ella, que, para ser posible, debe ejercerse dentro de unos límites que permitan la libertad de los demás en armonía con los intereses generales de la comunidad"32.

En estrecha concordancia con la lógica de la Corte Suprema, la Corte Constitucional sentenció ${ }^{33}$ :

"Esta Corte reitera que no es constitucionalmente de recibo, aducir el derecho a la propiedad privada, la libre iniciativa privada, la libertad

\footnotetext{
31 Corte Suprema de Justicia. Sala Plena. Sentencia de marzo 30 de 1978. Magistrado Ponente: Doctor Luis Carlos Sáchica Aponte, citada en Sentencia C-002 de 1993.

32 Corte Suprema de Justicia: Sala Plena. Sentencia de octubre 19 de 1971. Magistrado Ponente: Doctor Guillermo González Charry, citada en Sentencia C-002 de 1993.

${ }^{33}$ Sentencia C-332/00, expediente D-2565, MP Fabio Morón Díaz
} 
económica, la libertad de empresa y el derecho a la libre competencia económica como si se tratase de barreras infranqueables que pudiesen impedir la eficaz protección del interés público... las autoridades deben precaver, en cumplimiento del deber de prevenir abusos ... hacer efectiva la prevalencia del interés público, de salvaguardar los consumidores y de construir un orden justo.

No se olvide que el Constituyente de 1991 elevó a la categoría de mandato constitucional la protección de los consumidores y usuarios en el artículo 78 de la Carta; que en el artículo 335 ibídem, dispuso que las actividades financiera y aseguradora "son de interés público", y que de manera consonante con los anteriores, en el inciso final del artículo 334 señaló que "la ley delimitará el alcance de la libertad económica cuando así lo exijan el interés social, el ambiente y el patrimonio cultural de la Nación."

Es este el sentido del artículo 333 de la Carta cuando preceptúa que "la actividad económica y la iniciativa privada son libres, dentro de los límites del bien común" y que "la libre competencia es un derecho de todos que supone responsabilidades" (NFT) 


\section{2.- Principio de la Justicia Contractual}

Los redactores de los diferentes códigos modernos no fueron indiferentes a las exigencias de la justicia contractual ${ }^{34}$. La inclusión de instituciones jurídicas como las buenas costumbres, el orden público o la buena fe como requisitos de validez o deberes de conducta contractual así lo demuestran; incluso la institución de la lesión enorme responde a un imperativo mínimo de equilibrio contractual. A pesar de ello, es necesario reconocer que tales codificaciones apenas se preocupaban de la justicia conmutativa. Ello, debido a que tenían una concepción formal de la equivalencia de las prestaciones. En consecuencia la consideraban adquirida una vez que las partes estuvieran de acuerdo en los beneficios recíprocos a intercambiar. Adicionalmente hicieron caso omiso de las desigualdades sociales, las diferencias económicas, las situaciones de miseria, necesidad o crisis $^{35}$.

Sin embargo, con el paso del tiempo las diferentes preocupaciones por una justicia efectiva y material adquirieron fuerza como consecuencia de las diferentes crisis de orden económico y social que padeció el planeta a lo largo de las dos guerras mundiales. Enarbolando la bandera de los Principios Generales del Derecho (Supra) así como nociones tales como el orden público, los tribunales se han dedicado a enfrentar tales desequilibrios, aún en el ámbito contractual. Así por ejemplo, la jurisprudencia de los diferentes países europeos o latinoamericanos, aún sin la intervención del legislador, han edificado un sistema de revisión y

\footnotetext{
${ }^{34}$ PEDAMON, (M.), Le contrat en Droit allemand, 2004, Paris, LGDJ, n 23. Mazeaud Levy, Castaldo

${ }^{35}$ PEDAMON, (M.), Le contrat en Droit allemand, 2004, Paris, LGDJ, nº 23.
} 
adaptación de los compromisos contractuales, incorporando la teoría de la imprevisión ${ }^{36}$, por ejemplo.

La consagración constitucional del Estado Social de Derecho implica que los tribunales colombianos deben aplicar e interpretar la legislación en vigor bajo la perspectiva y con el objetivo de «permitir la edificación de un orden social más justo ${ }^{37}$. Ello implica que este modelo estatal orienta los diferentes poderes públicos hacia la justicia social, de tal manera que la desigualdad de oportunidades disminuya, protegiendo a los más débiles. Este principio involucra igualmente que los tribunales apliquen e interpreten la legislación en vigor con la misma perspectiva y objetivo. Desde luego, ello no quiere decir que los jueces puedan ejercer un control general de equidad sobre el contenido de los diferentes contratos; sólo podrán condenar, apoyándose en las normas de orden público, las estipulaciones contractuales establecidas por una parte que abusa de su superioridad económica o intelectual en perjuicio del otro contratante ${ }^{38}$. Este principio ha sido a este tenor reconocido por nuestra jurisprudencia constitucional en los siguientes términos ${ }^{39}$ :

“Partiendo de la falibilidad del legislador, esta Corporación afirmó que las reglas jurídicas, aun cuando estén impecablemente diseñadas desde el punto de vista técnico, no pueden llegar a contemplar todas aquellas hipótesis de hecho que hacen parte del acontecer social. En efecto, el

\footnotetext{
${ }^{36}$ PEDAMON, (M.), Le contrat en Droit allemand, 2004, Paris, LGDJ, $\mathrm{n}^{\circ} 25$.

${ }^{37}$ Preámbulo de la Constitución política de Colombia.

${ }^{38}$ PEDAMON, (M.), Le contrat en Droit allemand, 2004, Paris, LGDJ, $\mathrm{n}^{\circ} 25$.

${ }^{39}$ Sentencia C- $1547 / 00$
} 
derecho, como fenómeno de institucionalización y sistematización de cierto tipo de reglas, principios y valores, es un proceso social que se construye históricamente.

Dado el carácter histórico de este proceso, y particularmente respecto del derecho legislado, la equidad resulta de la aplicación de la justicia al caso concreto, según la máxima que prescribe que se debe "tratar igual a los iguales y desigual a los desiguales." Sin embargo, en un Estado pluralista, que reconoce la autonomía de los individuos, la realización de dicha máxima a partir de un conjunto limitado de categorías de igualación de las personas atribuida por la ley, no está exenta de problemas. Por ello, al estar inserta en el momento de la aplicación de la ley, la equidad permite llevar a la realidad dicha máxima y, en tal medida, corregir o moderar al menos dos problemas que surgen del carácter general de la ley." (NySFT)

Derecho comparado: Los planteamientos de nuestra Corte Constitucional lejos están de ser elaboraciones exóticas y arbitrarias que, como algunos han señalado, son atentados contra la seguridad jurídica e imposición del gobierno de los jueces, quebrantando de esta manera los valores democráticos. Por el contrario, nuestro alto tribunal constitucional no hace nada distinto a acatar el espíritu de nuestra Constitución, basada mayoritariamente en el modelo germánico. Y en Alemania, el Tribunal Constitucional Federal sigue enfáticamente las anteriores 
consideraciones; así por ejemplo, en sentencia del 7 de febrero de $1990^{40}$ manifestó que en donde no hay equilibrio aproximativo de fuerzas entre los contratantes, el Derecho de Contratos no puede de manera exclusiva y excluyente (esto es, por sus propios medios, aisladamente) garantizar una equivalencia satisfactoria de intereses. Posteriormente el Tribunal Constitucional alemán reprochó a la Corte Federal de Justicia el no haber tenido en cuenta la inferioridad estructural de una caución otorgada a favor de un banco, ni tampoco la carga extremadamente onerosa que se le había impuesto a la parte débil del vínculo contractual. En consecuencia, se reprochó al juez civil el haber violado los principios fundamentales de la autonomía privada así como del Estado Social de Derecho. Se puede verificar que semejante análisis armoniza las exigencias propias de la libertad contractual con las preocupaciones de un mínimo de justicia al momento de establecer un acuerdo de voluntades. Estas consideraciones son denominadas por la doctrina germana "Materialización del Derecho de Contratos" 41 .

\section{3.- Principio de Confianza en la Voluntad Declarada}

El principio de la libertad contractual, al cual todavía se adhiere la teoría posmoderna del contrato, a pesar de las limitaciones que se verifican en la actualidad, explica que las disposiciones aplicables a los contratos procedan en buena medida de una visión dogmática que hace énfasis en la voluntad interna,

\footnotetext{
${ }^{40}$ PEDAMON, (M.), Le contrat en Droit allemand, 2004, Paris, LGDJ, n 25.

${ }^{41}$ PEDAMON, (M.), Le contrat en Droit allemand, 2004, Paris, LGDJ, n 25.
} 
incluso íntima de los contratantes, a la hora de determinar su intención real y efectiva $^{42}$.

Sin embargo, en otros aspectos la visión posmoderna da crédito a la teoría de la declaración, la cual privilegia el aspecto exterior y objetivo de las declaraciones de voluntad; todo ello con el objetivo de proteger la seguridad del comercio jurídico. En efecto, se trata de asegurar la confianza depositada por una persona que actúa de buena fe en los diferentes intercambios económicos como consecuencia de lo que se manifiesta como la voluntad del declarante de turno, mediante el enunciado que ha efectuado. Se puede constatar que la jurisprudencia posmoderna tiende a acentuar esta protección basada en la voluntad declarada o aparente, principalmente basándose en la regla de interpretación de los actos jurídicos basada en criterios objetivos e incluso consagrando obligaciones cuya fuente reside en una simple apariencia ${ }^{43}$. Este principio propina un nuevo golpe a la primacía de la teoría de la autonomía de la voluntad. Es precisamente por ello que la Corte Constitucional colombiana ha sentenciado ${ }^{44}$ :

"En conclusión, mal puede considerarse a la autonomía de la voluntad como un poder omnímodo en cabeza de los particulares; los múltiples límites que se le imponen, la reducen a un simple ejercicio de potestades reglamentarias que el legislador otorga a los ciudadanos ${ }^{45, "}$.

\footnotetext{
${ }^{42}$ PEDAMON, (M.), Le contrat en Droit allemand, 2004, Paris, LGDJ, $\mathrm{n}^{\circ} 26$.

${ }^{43}$ PEDAMON, (M.), Le contrat en Droit allemand, 2004, Paris, LGDJ, $n^{\circ} 26$.

${ }^{44}$ Sentencia C-660/96

${ }^{45}$ Al respecto puede verse: Corte Constitucional, sentencia T-338 de 1993. Magistrado Ponente, Dr. Alejandro Martínez Caballero.
} 
Conclusión: estos principios y tendencias que dominan la teoría posmoderna del contrato en algunos ámbitos se complementan, pero de manera indudable en otros aspectos se contradicen ampliamente. Vale la pena reiterar dos ideas nucleares dentro de la concepción posmoderna del negocio jurídico: la noción de Principios Generales del Derecho así como la naturaleza relativa del imperativo de seguridad jurídica se enmarcan dentro de la más pura tradición romanista. En realidad, esta contradicción genera una tensión entre los imperativos de libertad y justicia contractual. Dicha tensión será constatada en estudios posteriores, acerca del contrato en tanto que fuente de obligaciones en un contexto de globalización.

\section{Referencias bibliográficas}

AAVV, Globalización, Integración Económica y Derechos Humanos, Universidad Sergio Arboleda, 2005, Bogotá.

Alexy, Robert, Tres escritos sobre los derechos fundamentales y la teoría de los principios (traducción de Carlos Bernal Pulido), Bogotá 2003

Corte Constitucional colombiana, sentencia C-002 de 1993

Corte Constitucional colombiana, sentencia No. T-338/93 
Corte Constitucional colombiana, sentencia C-224/94

Corte Constitucional colombiana, sentencia C-083/95

Corte Constitucional colombiana, sentencia C-660/96

Corte Constitucional colombiana, sentencia C-332/00

Corte Constitucional colombiana, sentencia C-1547/00

Corte Constitucional colombiana, sentencia C-836/01

Jiménez Cano, Roberto-Marino, Sobre Los Principios Generales Del Derecho. Especial Consideración en Derecho Español, http://www.filosofiayderecho.com/rtfd/numero3/1-3.pd

Judt T., Postguerra, Ediciones Taurus, 2ª Ed., 2008, Madrid.

Kaufmann A., Filosofía del Derecho, Universidad Externado, 2006, Bogotá.

Larroumet, (C.), Droit Civil, t. III Les obligations, Le contrat, 2003, Paris, Economica. 
Mantilla F. y Ternera F. (Directores Académicos), Los Contratos en el Derecho Privado, Editorial Legis, 2009, Bogotá.

Ortega M., Mecanismos de Defensa Frente a las Cláusulas Abusivas en los Contratos Internacionales, in Globalización y Derecho Mercantil, Biblioteca Jurídica Diké, 2008, Medellín.

Pédamon, (M.), Le contrat en Droit allemand, 2004, Paris, LGDJ

Sánchez C., El Impacto de la Globalización: Aspectos Económicos y Políticos en América Latina, in Globalización, Integración Económica y Derechos Humanos, p. 195 y ss., Universidad Sergio Arboleda, 2005, Bogotá. 